Child Advocacy Center intervention with sibling sexual abuse cases:

Cross-cultural comparison of professionals' perspectives and experiences

\author{
Dafna Tener ${ }^{1 *}$ \\ Abbie Newman ${ }^{2}$ \\ Peter Yates ${ }^{3}$ \\ Noam Tarshish ${ }^{1}$ \\ The Hebrew University of Jerusalem ${ }^{1}$ \\ Mission Kids Child Advocacy Center, Montgomery County, PA, USA ${ }^{2}$ \\ Edinburgh Napier University, Edinburgh ${ }^{3}$
}

\begin{abstract}
Author Note
${ }^{1}$ Dafna Tener, The Paul Baerwald School of Social Work and Social Welfare, The Hebrew University of Jerusalem, Mt Scopus, Jerusalem 91905, Israel; dtener@gmail.com; 972-527749219; The Haruv Institute, Jerusalem, Israel; ${ }^{2}$ Abbie Newman, Mission Kids Child Advocacy Center, Montgomery County, PA USA; ${ }^{3}$ Peter Yates, Edinburgh Napier University, Edinburgh, Scotland; ${ }^{1}$ Noam Tarshish, The Paul Baerwald School of Social Work and Social Welfare, The Haruv Institute, Jerusalem, Israel.

${ }^{*}$ Corresponding Author
\end{abstract}


Running Head: SIBLING SEXUAL ABUSE: CROSS CULTURAL COMPARISON

\section{Acknowledgements}

We are thankful to our colleagues and team members at the Mission Kids and the Jerusalem Child Advocacy Centers, who provided expertise that greatly assisted the process, and generously shared wisdom and experiences with us during the course of this research. We are especially grateful at the JCAC to Shosh Turgeman, the former Director of the JCAC, and to Lee Levi, for their dedicated assistance in explaining and interpreting concepts and procedures, making them accessible to the reader; and at MKCAC to Elizabeth Evans for her patience in precise note taking and proof reading, and Leslie Slingsby, Executive Director, for her understanding of this emerging field, all of whom improved and enhanced this paper. 


\title{
Child Advocacy Center intervention with sibling sexual abuse cases: Cross-cultural comparison of professionals’ perspectives and experiences
}

\begin{abstract}

\section{Background}

Despite being a complex phenomenon with potentially significant short- and long-term consequences for all involved including siblings, parents and the family as a whole, sibling sexual abuse (SSA) has not received sufficient empirical and clinical attention. Practitioners are often left to cope without appropriate guidance.
\end{abstract}

\section{Objective}

This study aimed to compare staff perspectives and experiences of working with sibling sexual abuse cases across two Child Advocacy Centers (CACs) within different countries and different cultural and legal contexts.

\section{Participants and Setting}

Participants were staff members from two Child Advocacy Centers: one in Jerusalem, Israel, and the other in Montgomery County, Pennsylvania, United States of America.

\section{Methods}

This qualitative cross-cultural comparative study analyzes staff experiences of sibling sexual abuse cases based upon 14 focus groups, in Jerusalem ( $N=7)$ and Montgomery County ( $N=7)$.

\section{Results}

Findings reveal that both CACs focused on parents, the parents' negative emotional responses to SSA, and the impossible nature of their predicament. The Montgomery County CAC tended to emphasize the needs of the victim while being attuned to the legal proceedings, whereas the Jerusalem CAC emphasized supportive therapeutic responses for the whole family.

\section{Conclusions}


The differences across the two Child Advocacy Centers are related to the different legal and cultural contexts of the two CACs and underscore the need to review what may be the most appropriate policy and practice response to SSA that does not itself cause further harm.

Keywords: Sibling sexual abuse; Child sexual abuse; child/youth with problematic sexual behaviors (PSB); CAC intervention; Child sexual abuse interventions; Cross cultural comparison 


\section{Child Advocacy Center intervention with sibling sexual abuse cases: Cross-cultural comparison of professionals’ perspectives and experiences}

\section{Introduction}

\section{Sibling Sexual Abuse: The Phenomenon}

Estimates of the prevalence of sibling sexual abuse (SSA) vary considerably (e.g. Russell, 1986; Atwood, 2007), but is thought to one of the most prevalent forms of child maltreatment (Meyers, 2017) and more common than sexual abuse by biological parents (Krienert \& Walsh, 2011). The term sibling sexual abuse is used to encapsulate a broad range of sexual contacts between at least two siblings in childhood and adolescence that are not considered manifestations of age-appropriate curiosity. It includes non-contact behaviors, such as watching pornography, and contact behaviors, such as fondling and forcible penetration (Haskins, 2003; Thompson, 2009). There are no universally agreed criteria for differentiating harmful from harmless sibling sexual behavior (Caffaro, 2014), but three indicators are typically applied: (1)Age or developmental difference (more than 2-3 years); (2) Severity (reciprocity vs. coercion; frequency, and duration); and (3) Underlying motivation (curiosity or precocious gratification) (Atwood, 2007; Ballantine, 2012; Carlson, Maciol, \& Schneider, 2006; Cicirelli, 1995; Hardy, 2001; Rudd \& Herzberger, 1999; Veigh \& Jo, 2003).

The literature tends to divide SSA relationships into two broad types: those involving manipulation, threats or coercion and thus a clear distinction between victim and perpetrator (Canavan, Meyer \& Higgs, 1992; McDonald \& Martinez, 2017) and those involving “sexual games," whereby sexual behavior progresses gradually under conditions of mutual affection, at least initially (Canavan, Meyer \& Higgs, 1992). In the second type, SSA relations may shift at some point when one sibling begins to object and participates only under pressure, and 
relations then begin to resemble the first type (Carlson, Maciol \& Schneider, 2006). Some authors differentiate between power-oriented and nurturance-oriented sibling sexualized relationships (Bank \& Kahn, 1982; Worling, 1995; Caffaro \& Conn-Caffaro, 2005). Siblings may turn to each other for comfort in the midst of high levels of family conflict, violence and abuse (Brennan, 2006), and this comforting may become sexualized. What starts as mutual behavior may in time become coerced (Griffee et al., 2016).

However, the ability to differentiate between developmentally normal sibling sexual behavior and inappropriate or abusive sexual behavior is somewhat compromised by a lack of definitive understanding of what is normal (Yates, 2017). Sexual acts tend to be less or nonabusive when the age or developmental gaps are small, when they are consensual and mutually pleasurable, and when their duration is limited (Atwood, 2007; Cicirelli, 1995; Hardy, 2001). Nevertheless, abuse does occur between similar-age siblings (Allardyce \& Yates, 2013; Krienert \& Walsh, 2011; Veigh \& Jo, 2003), without force being used (Cyr, Wright, McDuff \& Perron, 2002), and may also involve a combination of severe and less severe sexual acts (such as lustful stares) that victims may experience as equally harmful (Thompson, 2009). In the absence of large age gaps or the use of force, it may be necessary to examine the dynamics of the sibling relationship in order to understand the nature of the behavior (Allardyce \& Yates, 2013). Another concern is when the sibling with problematic sexual behaviors has himself been the victim of previous sexual or other abuse inside or outside the family (Allen, 2017; Silovsky \& Niec, 2002; Swisher, Silovsky, Stuart \& Pierce, 2008). In such cases it may be unhelpful to dichotomize the children as 'victims' and 'offenders'.

Further complicating the picture is the fact that, perhaps even more than other types of childhood sexual abuse, SSA is shrouded by popular myths including assumptions of normality, harmlessness and mutuality that have been challenged by multiple studies (Tapara, 2012). The life-long psychological implications of SSA may be at least as severe as other types 
of intrafamilial sexual abuse (Cyr et al., 2002; Monahan, 2010; Rudd \& Herzberger, 1999; see Tapara, 2012; Yates, 2017, for a review) and may include drug abuse, depression, hypersexuality and risky sexual conduct, as well as re-victimization (Beard et al., 2013; Carlson, 2011; Kiselica \& Morrill- Richards, 2007; Morrill, 2014; Stroebel et al., 2013).

The authors understand the importance of language and therefore the term that will be used in this paper is "child or youth with problematic sexual behaviors (PSB)" rather than “perpetrator" or "offender child.” Nevertheless, in the results section this paper utilizes the terminology used by the professionals in the focus groups, who often referred to the "victim child" and "offender child" to delineate their roles and responsibilities in the sexual behavior; therefore, for the purposes of this paper, the same terminology is used when quoting professionals participating in this research.

\section{Children's Advocacy Centers' (CACs) Interventions in Cases of SSA}

In 1985, Former US Congressman Robert E. “Bud” Cramer, who was then a prosecutor in Madison County, Alabama, USA, saw the need to create a better system to help sexually abused children. The social service and criminal justice systems at the time were not working together in an effective manner that children could trust, adding to the children's emotional distress when abuse was reported, and creating a segmented, repetitious, and often frightening experience for the child victims (www.nationalcac.org). CACs were thus formed to provide a multiagency response to investigations of suspected child sexual abuse by improving the coordination of the individual professional investigations (prosecution, law enforcement, social services, medical and mental health) to be more victim centered. This concept requires that the professionals come to the child at a child-friendly center, acting in a coordinated and developmentally appropriate fashion for each child, promoting more informed professional decisions and a minimization of the trauma children can suffer following disclosure of Child Sexual Abuse (CSA) and the subsequent investigation. There are now approximately 1,000 
CACs in the United States, and the model is being utilized in 33 countries around the world (www.nationalcac.org).

SSA is less likely to be reported to law enforcement or welfare authorities than some other forms of child maltreatment. Studies suggest lack of reporting may be due to parents adopting a benign interpretation (Bass, Taylor, Knudson-Martin \& Huenergardt, 2006; Cyr et al., 2010; Rayment- McHugh \& Nisbet, 2003), doubting the report or blaming the victim (Walsh, Cross \& Jones, 2018), minimizing and denying the abuse because of shame associated with SSA, or a belief that it is just normal sexual exploration (Krienert \& Walsh, 2011). Selfdisclosure of SSA, whether to someone within or outside the family, appears to be rare (Caffaro \& Conn-Caffaro, 2005; Finkelhor, 1980). Children who do disclose usually talk to their parents (Gomes-Schwartz, Horowitz, \& Cardarelli, 1990; Lamb \& Edgar-Smith, 1994; Lynch, Stern, Kim Oates, \& O'Toole, 1993). In other cases, the behavior may be directly witnessed by parents, or neither disclosed nor witnessed but strongly believed to have taken place (Yates, 2015).

Professionals who work with families and victims after the disclosure of SSA meet them in a time of great distress. These families are often required to make difficult decisions, such as how to protect the victim and whether to exclude the child with PSB from the family home (Lafleur, 2009). There is consensus in the literature that legal and therapeutic intervention should be multidisciplinary and consider the needs of the entire family, from the moment of disclosure to the end of therapy (e.g. Thomas and Viar, 2005; Haskins, 2003). Cases of SSA frequently require the involvement of a large number of health and social care professionals, each of them often working with a different family member (the child with PSB, the victim, other siblings, and the family as a unit). Noteworthy is the work that was done in California, USA, about 40 years ago by the Child Sexual Abuse Treatment Program (CSATP) which included all the officially responsible members of the community: police, social 
workers, mental health workers, probation officers, defense and prosecuting attorneys, judges and rehabilitation officers, and focused on comprehensive in-depth therapy to all members of the family in cases of incest as an alternative to the legal intervention (Giarretto, 1978, 1982).

\section{The Rationale for the Current Study}

SSA has yet to receive sufficient empirical and clinical attention, leaving professionals to cope with these uniquely complex cases without appropriate scientific guidance (Harper, 2012).

CACs stand at the frontline of dealing with cases of SSA as part of their daily routine. Therefore, the current study aims to explore CAC staff and team member experiences and views concerning the therapeutic and legal interventions in SSA cases, and what they consider to be the particular practice challenges. This study uses the term "therapeutic intervention" to mean crisis intervention or referral for provision of mental health therapeutic services. "Legal intervention” is used to refer to legal processes and procedures such as law enforcement, prosecutors and/or family court personnel and the legal processes is involved. Comparing two CACs, one located in Jerusalem, Israel, and another in Montgomery County, Pennsylvania (PA), United States of America (US), offers the opportunity to explore the differences and similarities in their experiences from a cross cultural perspective. The study addresses the following questions: (1) How do CAC staff and team members experience and perceive cases of SSA; how do their experiences in these cases differ from other cases of child sexual abuse? (2) How do they experience and perceive the CAC's interventions in cases of SSA, and what are the unique challenges they face while dealing with these cases? (3) What are the differences and commonalities between the CACs' interventions from a cross cultural comparison?

The Context for the Present Study: CACs' Interventions in SSA Cases from a Cross Cultural Perspective 
As noted above, CACs are based on an American intervention model that provides therapeutic and legal responses to victims and their families after the discovery of child sexual abuse, including acute crisis intervention not only for the child victim, but also for all nonoffending family members (Jackson, 2004; Jones, Cross, Walsh, \& Simone, 2007). CACs streamline case management, minimize investigative interviews, and protect the wellbeing of children and their families by bringing together medical, legal, and child protection service workers to one site. Staff members at CACs provide specialized, coordinated evaluations in a child-friendly setting aimed at reducing the emotional impact of disclosure, mitigating the long-term effects of abuse and disclosure, and reducing or eliminating the risk of future victimization (Miller \& Rubin, 2009; Rasmusson, 2011; Tavkar \& Hansen, 2011). It should be noted that CACs are not focused on the alleged child with PSB and do not intervene with alleged children/youth with PSB, with the possible exception of young children with PSB. In Israel, if the child with PSB is under the age of legal responsibility of 12 years of age, the Child Protection Officer (CPO) in the Jerusalem Child Advocacy Center (JCAC) may undertake a risk assessment and recommend therapeutic intervention. CACs in the US may refer the sibling with PSB for therapeutic intervention if they are below the age of prosecution for that jurisdiction, and child welfare agencies may not have the ability to intervene. However, many children with problematic sexualized behaviors do not receive any referrals, or appropriate referrals may not be available in many communities.

Even though they are based on one model, CACs differ from one another and are influenced by legal, organizational and cultural aspects. The present study was based on two CACs, one located in Montgomery County, Pennsylvania, United State of America, and the other in Jerusalem, Israel. The following section describes each of these Centers, including the circumstances of their construction, staff, and facilities as well as policies and protocols of each CAC. 


\section{The Mission Kids Child Advocacy Center (MKCAC) of Montgomery County, Pennsylvania, United States of America}

Background. Planning for MKCAC began in 2004 as a partnership between the Montgomery County Office of Children and Youth (the county child welfare organization), the Montgomery County District Attorney's Office, and the Police Chief's Association of Montgomery County. In 2007, it was decided that the organizational structure for MKCAC would be a non-profit organization, which is the equivalent of a non-governmental organization (NGO). Oversight of MKCAC is governed by a 30-person Board of Trustees, which includes the District Attorney (chief prosecutor), a Chief of Police, business leaders, philanthropists, a survivor parent, the Chief Executive Officer (CEO) of MKCAC, and the Executive Director of MKCAC. MKCAC opened in 2009 to serve alleged victims of CSA, serious physical abuse, and child witnesses to violence. Children are of all ages, from when they are verbal through age 17. At the time of acceptance for publication, MKCAC has worked with almost 5,000 alleged victims.

Legal frame of operation. CACs are not mandated by law in Pennsylvania; it is up to each county (67 in PA) to decide if they want a CAC, and if so, if it should be a non-profit, a government service, part of an umbrella corporation, or located within a hospital. Cases of suspected CSA, serious physical abuse, or child witnesses to serious or violent crime can be referred to MKCAC by the police, prosecutor, or county child welfare agency; MKCAC does not accept community referrals or walk-in clients. The protocols for response by MKCAC are the same, regardless of which agency referred the case.

Staff, facilities, and multidisciplinary team. In addition to the CEO and Executive Director, MKCAC staff includes 4 Forensic Interviewers, 4 Family Advocates, a Case Coordinator, and administrative staff performing fundraising, bookkeeping, and support staff work. The facility is 5,900 square feet and includes a waiting area with older and younger 
children's spaces, 3 interview rooms decorated for children of different ages, 3 observation rooms from which the multidisciplinary team watches the forensic interview via closed circuit television, family rooms for private meetings with the staff and team members, one therapy office, staff offices, and kitchen space.

The population of Montgomery County is approximately 800,000 people. There are 50 independent police departments plus the County Detective Bureau, and so police representation on the multidisciplinary team will vary with the location of each case. Additionally, child welfare/social workers will vary based upon which team at the child welfare agency is involved, and any one of 4 or more prosecutors will be involved in cases of children with problematic sexualized behaviors. Therefore, there is always a unique multidisciplinary team formed in response to each case.

MKCAC has developed partnerships with specialized medical practitioners in CSA and mental health therapists who provide evidence-based, trauma-focused mental health treatment to CSA victims and their families. Interventions are not provided to adult perpetrators or children/youth with PSB except in cases where the youth with PSB also has a history of victimization and associated symptomatology.

Intervention processes. The intervention processes at the CAC include several steps, and are based on legal and crisis management components. At the beginning, police, child welfare, prosecutor, family advocate and forensic interviewer team members meet to exchange pertinent information at the CAC immediately before the investigative forensic interview with the child victim. The victim child is then interviewed by a specially trained Forensic Interviewer (FI), while the prosecutor, child welfare caseworker, and police observe the interview via closed-circuit television in an adjoining room. While the forensic interview is taking place, the Family Advocate (FA) meets with the parent or guardian non-offending family member(s) to determine if medical, mental health or community interventions are 
needed and begins making those connections. When the interview is concluded, team members meet with the non-offending family member(s) to tell them the results of the interview and their next steps. Each team member will then continue providing their own professional involvement with the child and family and keep in touch with the other team members outside of MKCAC. Cases can be brought back to MKCAC at the request of any team member at a later date for a case review by all team members to evaluate the progress or challenges encountered in a specific case. If indicated, the FA will continue to work with and help each family navigate the complex legal, medical, mental health and community systems after the interview. The FA intervention may include administering a screening tool to assess children's mental health, providing referrals to mental health services, and connecting families with community resources to address needs including concurrent domestic violence, housing, clothing, food, and caregivers' mental health and medical needs.

Sibling sexual abuse considerations and prevalence. In Pennsylvania, child welfare professionals are responsible for the investigation of child abuse reports to determine whether the alleged offending adult or child over 14 years of age would be appropriate to remain in child caregiving settings or be prohibited from working or volunteering in a setting involving child care. Child welfare professionals are also responsible for ensuring caregivers can provide a safe environment for children. If the alleged child with PSB is under 14 years of age, and the child welfare professionals do not think that another child is in continuing danger, child welfare professionals may not be involved with the SSA case and it will be categorized as "Law Enforcement Only.”

There are no separate protocols in place for children who are victims of SSA versus other types of child sexual abuse. Under the Pennsylvania Juvenile Law, prosecutors cannot bring criminal charges against children under the age of 10, but forensic interviews and FA interventions are still provided for all alleged victims, even if the alleged abuser is younger 
than 10 years old. In 2017, MKCAC served 579 children; 464 of those children were victims of alleged CSA, and 37 of those cases involved SSA.

\section{The Beit Lynn Jerusalem Child Advocacy Center (JCAC)}

Background. The JCAC is the first CAC in Israel, established in 2002. CACs have been mandated by law in Israel since 2008, and since then an additional 7 CACs around the country have been established. The JCAC was based on the American model, described above, and several governmental and private organizations were part of the initiation for its establishment.

Legal frame of operation. In Israel, the CAC is supervised by the Social Services Ministry in partnership with the Ministry of Homeland Security, Ministry of Justice, and the Ministry of Health. The CAC is funded and supervised by the government but operated by an

NGO. Cases of suspected CSA, serious physical abuse, or child witnesses to crime can be referred to JCAC by the police, local social work agency, education system, health systems (e.g., hospitals), or private therapists. Individuals from the community can also come to the CAC independently for help.

Staff, facilities and multidisciplinary team. The building renovation and all of the equipment are funded by a private foundation. Staff include the Executive Director who is a social worker, two child protection officers (CPOs-social workers), a police officer, two child investigators, a physician, a legal counselor, a secretary, and a housekeeper. The facility is about 4,300 square feet, and includes 3 waiting areas for older and younger children, 3 rooms for the CPOs, 2 interview rooms for the forensic interviewers, 2 observation rooms, which are also the police officers' offices, a room for medical examinations, and 4 meeting and staff rooms. It also includes a kitchen which can serve light refreshments for the children. The CAC's courtyard features a spacious garden and playground facilities for children. The JCAC 
interventions are provided to CSA victims and their families including children under 12 years of age who are alleged to have PSB.

The population of the JCAC includes the city of Jerusalem and its surroundings, a population of over 1,300,000 people. The JCAC is part of The Haruv Institute. The Haruv Institute is a leading organization for training professionals, providing support for researchers, and developing and disseminating innovative professional knowledge in prevention and intervention for children who have experienced abuse and neglect. Haruv's mission is to promote knowledge and training with all professionals in the field, specifically with "anyone who comes in contact with children” (Haruv.org.il). Haruv Children’s Campus is contained within the Haruv Institute, a university campus, which in addition to the CAC includes 8 other organizations that focus on services for maltreated children, all under the same roof.

Intervention processes. The intervention in the JCAC includes legal and therapeutic components and follows several steps. At the beginning of the intervention, team members meet to exchange pertinent information about the case. At this stage they may decide that the case is appropriate for legal intervention, and if so, the child victim would be forensically interviewed inside the Center. It should be noted that if youth with PSB are above the age of 12 (the age of legal responsibility), there is a possibility of criminal proceedings and indictment, which would be addressed outside of the CAC.

Alternatively, staff members can decide that the case may be appropriate for therapeutic intervention instead of immediately referring the case for legal intervention. If this is the case, there is a special committee in Israel called the "Exemption Committee," which can allow a temporary exemption from reporting to the police and a referral instead for therapeutic intervention. The composition of the Exemption Committee is determined by law, and its members include a senior representative of the State Prosecutor's Office, a police officer, and a district-level CPO (OECD, n.d.). There are several Exemption Committees around the 
country (per jurisdiction). Criteria for referral to the Exemption Committee include a combination of the characteristics of the youth with PSB (e.g., Does the child admit and regret the abusive acts, and is the child willing to receive treatment?), the age and understanding of the victim, the level of parents' cooperation and support, and the severity of the abusive acts. There is no time limit for the temporary therapeutic exemption; it can last for a month or more than a year. The CPO in the community who is responsible for the family is obligated to report to the Committee on the progress of the treatment, and the Committee has the authority to grant a permanent exemption or to cancel the temporary exemption and order legal intervention. The Committee's role is determined by the mandatory reporting law, but other than that, there are no published criteria for granting the exemption (Nahmani Roth, 2010). Finally, to our knowledge, there is no empirical study that has examined the long-term outcomes of the Exemption Committee on the lives of victims and other family members.

If a staff member decides that the case may be appropriate for referral to the Exemption Committee, the CPO meets the parents for an intake interview. The CPO then brings the case to another multidisciplinary team consultation and they decide, with the information gathered from the parents, whether the case should be referred for legal intervention or if more information should be gathered. If it is decided that the case requires legal intervention, the case will be reported to the police, and the child victim will be forensically interviewed. However, if the staff assess that therapeutic intervention is indicated, the CPO then interviews the victim siblings as well as the alleged sibling(s) with PSB if they are under the age of 12 (without parents), and other siblings in the family. These interviews are not recorded, are not structured as a forensic interview, and are intended to gather more preliminary information. The CPO then invites the parents to another meeting to assess levels of cooperation and protection. Finally, a multi-disciplinary team meeting is held and decisions are made regarding the direction of the intervention: legal intervention, including a forensic child interview, or 
referral to the Exemption Committee, at least temporarily, for therapeutic intervention directed to all family members.

SSA considerations and prevalence. There are no separate protocols in place for children who are victims of SSA. Under the Israeli Juvenile Law, prosecutors cannot bring criminal charges against children under the age of 12 . However, therapeutic interventions and at times forensic interviews are still provided for all alleged victims, even if the alleged child with PSB is younger than 12 years old, in order to understand the emotional states of both victim and siblings' with PSB, as well as the circumstances of the abuse. In 2017, the JCAC served 615 children; 569 of those children were victims of alleged CSA, and 137 of those cases involved SSA. The difference in sample sizes between the MKCAC and JCAC may be due to different cultural constructs, as in Jerusalem there are many intact families with large numbers of sibling children (Tener, Luski, Tarshish \& Turjeman, 2018). In such families it is more likely that multiple siblings within the same family will be involved in the sexual acts (Tener, Tarshish, \& Turgeman, 2017). Accordingly, in the JCAC there was often more than one sibling victim per family which would also contribute to the difference in sample size. Families in MKCAC, however, had fewer sibling children and often had blended families with step-children and single-parent households. Blended families often present a source of ambiguity for professionals, who may be unclear about appropriate sexual boundaries making sexual issues between step-siblings particularly hard to negotiate (Caffaro \& Conn-Caffaro, 2005).

This current cross-cultural study aims to explore CAC staff and team member experiences and views concerning the therapeutic and legal interventions in SSA cases, and what they consider to be the particular practice challenges. The cross-cultural study addresses how CAC staff and team members experience and perceive cases of SSA; how they experience and perceive the CAC's interventions in cases of SSA; and what the differences and commonalities are between the CACs' interventions. 


\section{Method}

\section{Setting and Participants}

Data collection included 14 focus groups, which took place between December 2015 and June 2018. Focus groups are a traditional and proven method for generating research data concerning meanings, perceptions, beliefs and collective views (Morgan, 1998). Groups may enable a more informal and relaxed setting for participants to express their thoughts and beliefs, and their sense of belonging can create opportunity for interactions and discussions (for review see Onwuegbuzie, Dickinson, Leech \& Zoran, 2009).

Seven focus groups were conducted with staff members in JCAC, each group meeting between 1 to 1.5 hours. The first author introduced the study to the JCAC group during a staff meeting and invited them to participate. Seven focus groups were also conducted with MKCAC team members. The second author sent an e-mail invitation to the numerous team members who work on SSA cases at the MKCAC and asked for voluntary interest in participation. Those team members who expressed interest were invited to attend the focus groups. In both groups it was emphasized that taking part in the study was voluntary, and all participants freely signed participation consent forms.

The focus groups were directed by the first author. The 7 groups in Israel were conducted in person, while 6 focus groups in Montgomery County were conducted via Skype, and one focus group was conducted in person. Each session was attended by between 4-18 participants, all of whom were multidisciplinary team and staff members of the CACs. The Israeli focus groups included social workers, child investigators, law enforcement officers, a doctor, prosecutors, a case coordinator and a secretary. Each Israeli meeting included the same core multi-disciplinary group (5-10 participants in each session), who participated in multiple focus groups, although during the study period some were workers who had finished their work at the CAC and others were new employees who agreed to take part in the research. 
The Montgomery County focus groups were organized differently to account for the numerous individuals who could be involved in different teams investigating allegations of SSA. One focus group was conducted with mental health professionals (4 participants); one group with law enforcement professionals (5 participants); one group with Office of Children and Youth caseworkers (child welfare) (18 participants); one group with Mission Kids staff (family advocates, the Executive Director and forensic interviewers; 9 participants); and 3 groups containing a full complement of multi-disciplinary team (MDT) members (forensic interviewers, family advocates, law enforcement, child welfare, and mental health professionals) with 5-9 participants per focus group, some members participating more than once.

The Israeli group was conducted in Hebrew and the US groups in English. At the beginning of each focus group, the researcher (first author) introduced a general question concerning SSA cases, such as, "Tell me about the SSA cases that have been treated in the Center, and how do they differ from other cases?” This was followed by encouragement by the first author for group members to participate in a discussion between themselves. The discussion was followed by more specific questions derived from the literature, concerning: (1) the abused siblings and siblings with PSB ("Could you describe the characteristics of the victim siblings?”; “Could you describe unique characteristics of siblings with PSB, and do they differ from other youth with PSB or other adult perpetrators?”); (2) the parents' characteristics (“Tell me, how do you perceive the parents of SSA cases during the intervention at the CAC?”); (3) and their perceptions of CAC interventions in SSA cases ("How do you intervene in cases of SSA and how do you perceive them?”; “What are the unique challenges these cases pose?”) The focus group was directed using open-ended questions by the researcher (first author), which enabled the group members to talk freely about their experiences and elaborate on the topics which were meaningful to them. In the JCAC, each one or two sessions included one 
topic (e.g. parents in cases of SSA), while in the MKCAC the groups conducted with specific professionals included the same issues for direct comparison, and the meetings with the Mission Kids staff and mixed team members dealt with different issues. Each focus group in Israel was transcribed by a research assistant or a secretary, who was present during the session. In Montgomery County there were 2 CAC staff transcribing during the sessions, and these notes were combined and forwarded to the first author. The first 6 focus groups in Montgomery County were conducted via Skype in real time, and the last group was conducted by the first author in person. Focus groups were transcribed and entered into MAXQDA software for analyzing qualitative data (the JCAC focus groups were first transcribed in Hebrew and then translated into English). The study obtained the approval of the Israeli Ministry of Welfare and Social Services and the Ethics Committee of the Hebrew University of Jerusalem. As there was a need to maintain the anonymity of the group participants, no details are given about the participants themselves, and the only indication is the CAC location in which the group was carried out (MKCAC, Montgomery County, United States or Jerusalem, Israel) and the group number in ascending order.

\section{Data Analysis}

We used a qualitative, thematic analysis approach (Braun \& Clarke, 2006) in order to analyze the transcripts from focus groups in both countries. This included several interrelated stages. Before beginning the analysis, the interviews were read several times in order for the author to become familiar with the data and to identify initial ideas. In the first stage, each interview transcript was entered as a case into the computer program (MAXQDA). Open coding was performed to elicit initial categories: the cases were broken down into small segments of text, representing discrete "units of meaning,” and each unit was labeled according to its content. 
In the second stage, the codes were grouped together as initial themes. As the author read the cases, some of the themes were removed or changed and additional codes and categories were added. For example, several codes were defined as "parents’ responses: feeling shame," whereas others were defined as "parents' responses: feeling confused”; or "parents' responses: divided loyalties between siblings.” In the third stage, the themes and subthemes were reviewed and classified by their dimensions and properties (Corbin \& Strauss, 2008). For example, all the various perceptions of parental responses related to the SSA were merged and separated from all other topics and grouped together.

Finally, in the fourth stage, themes were refined, named, and interrelationships between them were suggested (Braun \& Clarke, 2006). For example, the previously identified themes of perceived parents' responses were further classified into "Parents are so torn" and "CACs' professionals' experience with parents of SSA cases" which contained all perceived parents' responses and the way they were explained and interpreted by professionals in the two CACs. At this stage, the author referred back to the transcripts to retrieve additional information as required to develop the categories (Maykut \& Morehouse, 1994). Once all stages of the analysis were completed, comparisons were then made between the US and Israeli samples to identify themes reflecting commonalities and different experiences and perceptions.

These analyses have been performed by the first author, a lecturer in social work specializing in child sexual abuse and qualitative research methods. Selected excerpts from the source materials were discussed throughout in several peer debriefing sessions, with the second author, the Chief Executive Officer of the MKCAC, the third author, lecturer in social work specializing in child sexual abuse and qualitative methods, and the fourth author, a doctoral student in social work specializing in child abuse and neglect. The audit trail included detailed documentation of all analysis stages, with raw excerpts attached to all interpretations (Creswell \& Miller, 2000; Lincoln \& Guba, 1985). The entire analysis process was 
accompanied by reflexive writing by the authors on their ideas, perceptions, thoughts and feelings as they evolved (Cope, 2014; Nowell et al., 2017). The findings of the analysis were presented to both CACs' members via oral presentation in order for the participants to examine the data and comment on themes identified by the researchers. Their verbal comments and reflections on the data were then included in the analysis. Participants nearly always approved the authors' interpretations, explicitly stating that they were consistent with their experiences.

\section{Results}

The two main themes which emerged from the data, and which seemed to be the most meaningful for the participants in both CACs, included: (1) Their experiences with parents during their encounters at the CAC and, (2) their experiences and perceptions of the legal and therapeutic interventions conducted in the CACs in SSA cases. Both of these issues will be further discussed here, with illustrating quotes and emphasis on cross-cultural comparison between the two CACs.

\section{“Parents are so torn": CAC’s Professionals Experience with Parents of SSA Cases}

When participants in both CACs were asked by the researcher moderating the groups to reflect on SSA cases they deal with during the course of their work and how they differ from other cases, they described these cases as probably the hardest they deal with, using the terms “difficult” and “complex” repeatedly as illustrated in one of the participant's words:

'... These cases are the most emotionally complex for us as a team, as for these parents and kids... [The victims] are hurt by the offender, by the parents, by the [legal] procedure. There are tremendous emotional implications here...' (JCAC, group no. 2.) One of the particular challenge's participants identified was their work with parents, including the dilemmas faced by parents themselves, and the participants' struggles with some of the parents' responses. Interestingly, although they were asked during the focus groups to describe 
various aspects of their work with SSA cases, participants in both Montgomery and Jerusalem CACs placed the issue of parents in SSA cases as a central theme.

One participant from the MKCAC explained the nature of the parents' predicament:

'The biggest issue we run into [is] the parents. They struggle with how to protect the victim child and the offender. It prevents reporting and cooperation. How do I protect one kid without harming the other one?' (MKCAC, group no. 4).

Participants from both CACs described their encounters with parents in various ways, including their perceptions about parents' emotions and responses to the discovery of SSA and the imminent conflict they were confronting, being the parents of both the victim and the alleged sibling with PSB. Participants described parental struggles as including the necessity to protect the victim's siblings from further abuse, ensuring that they received therapy while, in the meantime, accompanying the sibling with PSB throughout legal proceedings.

Participants in both groups described multiple, negative feelings parents experienced after the SSA disclosure and the CAC becoming involved in their lives. Members of the JCAC, when referring to parents upon their arrival to the CAC for the first time after the SSA disclosure, used words such as, "These parents are in such state of anxiety. They are on the edge." (JCAC, group no. 4), and "When parents arrived because of SSA you can see how they are broken. They enter the room with such heaviness, and they look totally different from parents whose child was abused by someone else [not a sibling]." (JCAC, group no. 6).

The two teams recalled parental feelings of shame, self-blame, fear, and confusion that accompanied the parents when they arrived at the CAC. They described experiences of parents' helplessness and uncertainty. Participants also described that some of the parents tended to deny or minimize the abuse, by describing it as not serious or suggesting the victim might have misinterpreted the behavior as sexual. Some participants described parents' attempts to conceal the abuse from both the professionals and the extended family members, or being defensive 
and resisting CAC intervention. Participants in both CACs also described the harsh conflicts parents confronted, realizing that their children were now categorized by authorities as "victims" and "child with PSB," and that they themselves found it so difficult to understand that the same definitions should now be internalized by their family:

'What stands out most to me is how it's more difficult to work with parents on sibling on sibling cases than on other cases because parents are so torn. A huge element that's different is the hard position they're in, trying to accept that one of their own children has done this... abused another.' (MKCAC, group no. 3)

And in another group:

'We do more crisis counseling and prevention with sibling sex abuse cases as we are often the first people the parents are speaking to [about the abuse.] You can almost see the whole scenario playing out in their heads. How do I protect my victim child? How do I show my son, the perpetrator, that I still care about him without making my victim child think I'm not supportive?' (MKCAC, group no. 1)

Participants in both countries emphasized the great difficulty for the parents to provide for the needs of both of their children. Both CACs' participants also described how, in many cases, parents appeared to support the sibling with PSB rather than the victim:

'I do not really remember the parents but remember that they supported the offender and instead of condemning his actions, they abandoned the victims. I do not know why it happened in this family but yes if I connect it to my family... the most basic security that accompanies me is that my parents were there for us all the time. I wonder if these children felt their parents are their anchor? Perhaps if they did, it would have prevented these children from looking for "comfort" in each other. Once the parents decided to split and only go with the offender I knew they were not there for the victims.' (JCAC, group no. 3) 
What seems to differentiate the MKCAC from the JCAC are their interpretations of the parents' responses during the intervention. In the MKCAC team some of the professionals described justifications for parents' negative responses (such as denying or minimizing the abuse or supporting the sibling with PSB at the expense of the victim), but most of them concentrated on parents' level of cooperation during intervention, and on their ability to support the victim, as illustrated in the following quote:

'It really depends on the parents' response. If they are minimizing, it impacts the team negatively. If parents want to help both kids, there is a more positive response [from the team]. It's tough to see and hard to accept when parents totally side with the perpetrator vs. hearing them say, “Let's try to help our kids.”' (MKCAC, group no. 5).

In most cases the JCAC team seemed to be more focused on parents' circumstances. Though some of them were frustrated with parents' responses, most were focused on SSA being a family crisis and the parents' situation as unbearable. For example, when the parents sought out the CAC for help and then were told that the case may need to be reported to the police instead of using only therapeutic interventions:

'The other side is that [parents] come and because of their anxiety they minimize and do not say and we perceive it as if they were lying. It is very difficult to judge parents in such anxiety. They are on the edge when they know they can reach to safety or the abyss... The word "police” ... it's hard to judge them' (JCAC, group no. 1).

The Israeli team perceived the legal intervention as often leaving the parents with great responsibility towards the sibling with PSB (navigating through prosecution or being asked to supervise the sibling with PSB at any given moment in order to prevent further abuse), while the victims, as perceived by participants, tended to receive more support from the formal authorities. This is further illustrated in the following quote: 
'Many times, all energies are directed at the offending brother. Finding solutions where he will sleep, what will happen to his school... all the family's emotional and technical resources and the parents' concern incited empathy mostly to him. All the criminal procedures and the out of home arrangements.... The victims come out with guilt because the perpetrator must leave the house and all the family organization, which is all the time... When the victim knows that the perpetrator has been arrested because of her, it breaks her.' (JCAC, group no. 2)

The participant in this quote indicated that the parental focus is on the sibling with PSB, and offers an explanation that it may result from the formal legal intervention, which is aimed at ensuring safety, as well as the complicated legal procedures. Parents' unequal responses towards the sibling with PSB and victim sibling could also be a reflection, as described in other focus groups, of the fact that the victim already received support from the CAC as well as referral to therapy, while the sibling with PSB is perceived by the parents as being in danger. Yet the participant also referred to the consequences for the victim and the feeling of harsh blame they will carry, feeling they are responsible for causing a family crisis.

In sum, participants in both focus groups described various stressful parental responses during their encounters at the CACs, including the conflict between supporting their victim child and their child with PSB, and the common tendency to side with the child with PSB, a choice that heavily related to parents' needs to deal with formal legal intervention demands. Perceptions concerning the parents seemed to change according to the focus of each CAC intervention: Professionals in the US CAC were focused on the victim, while professionals in the Israeli CAC regarded the family system as the focus for their support, as further described in the following theme, which deals with intervention.

Who is The Target? Perceptions on Interventions in Cases of SSA 
During the analysis of the focus groups in both countries, it became clear that although both CACs aim to provide the best intervention in cases of SSA, the MKCAC focused heavily on how interventions would affect the victim (victim focused) and legal interventions that were needed on his/her behalf (legally focused), with less consideration given to other family members. In contrast, the Israeli CAC was both victim and family focused, with more emphasis on the family focused approach. "Family focused" is defined for this study as meaning that the interventions were provided based upon what was best for the family, which includes the victim, the child with PSB, parents, and other siblings. The MKCAC perception is emphasized in the following quote:

'When prosecution is talked about, parents most often ask if there's any way the sibling offender can get services after the forensic interview rather than jail time, like intense counseling or inpatient treatment programs. Parents want to avoid going through the criminal justice system, but law enforcement writes their report and the D.A.'s office decides what charges can be pressed, if any.' (MKCAC, group no. 1).

And in another focus group:

'Sibling Sexual Abuse is worse than unrelated offenders - younger and for longer time, by someone you love and trust; longer lasting developmental and psychological effects. I agree that they should be registered as a sex offender for life...; I am personally not “treatment heavy."' (MKCAC, group no. 5)

These quotes illustrate the tendency at the MKCAC to evaluate cases from a legal focus, as well as the perceived clear dichotomy between victims and alleged siblings with PSB. There were also other comments at the MKCAC that tended towards showing a need for legal responses instead of an initial therapeutic response. Such perceptions do not necessarily reflect the personal views of all MKCAC participants, but rather the legal mandate under which they operate. In most of the focus groups the participants did not tend to question the legal 
procedures involved in cases of SSA, but when prompted with a question concerning whether the legal procedure is the best solution in SSA cases, some of the US CAC members reflected on the possibility it may not be ideal in cases of SSA:

Participant 1: It's rare for the sibling perpetrator to get services. To get services, they would have to go through the law enforcement system.

Participant 2: Other places have figured out how to get services without the justice system.

Participant 3: Wouldn't the family be more open to the process if they knew services would be provided rather than going through the juvenile justice system?

Group: Agrees... "Yes.”

Participant 2: There might be more meaningful family engagement. (MKCAC, group no. 1.)

The evaluation of cases from a legal focus embedded in the US CAC legal mandate may also affect perceptions concerning living arrangements after SSA disclosure. Most of the MKCAC participants referred to the sibling with PSB's removal from the home as a vital, unavoidable step in order to protect the victim sibling, as illustrated in the next quote:

'[The mental health provider] would not take the case if the offending child is left in the home. You can have cameras all over the place, but without separation the victimized child can't experience a feeling of safety.' (MKCAC, group no. 2)

Yet it should be noted that some exceptions were made concerning cases where the siblings are young in age or when it was a one-time event as opposed to more severe cases when coercion and secrecy are involved. In the JCAC, the focus was less on out of home arrangements, and more on the ability to build a safety plan with the family which would ensure the cessation of any further abuse. 
As opposed to this straight forward approach to legal intervention of the MKCAC participants, the JCAC team was more ambivalent towards the legal intervention and mostly seemed to perceive such intervention as a deepening of the family crisis as illustrated in the next quote:

'A family that was with me yesterday...had no idea about the mandatory reporting. They did not know much and came to us as experts. The girl told me about a very, very serious continuous abuse, and when I updated the parents, it was as though I dropped a bomb of what happened in the family and another bomb on the mandatory reporting. The shock on the faces of the parents ... They were not able to contain this. They did not fight me or try to minimize, but they were just in shock...Instead of helping the [abused] child, the focus has shifted to how to deal with the criminal procedure...It rips me apart and rips the family apart...' (JCAC, group no.5)

Such attitudes can also be explained by the legal mandate of the JCAC. As opposed to the MKCAC, which is required to report cases of SSA to the police, the JCAC is able to use the Exemption Committee as a mechanism (see introduction) which enables them to get an exemption from immediately reporting the case to the police, referring the family to treatment instead. This mechanism enables flexibility and an opportunity for the professionals to assume a therapeutic role in the relationship with the families, as emphasized in the next quote:

'We find ourselves in a dilemma; we are subjected to a lot of pressure because of the law that binds me and the default that is the mandatory reporting. I have parents who are sensitive and hurt and are in an impossible position of choosing between one child and another. I am the one who is supposed to help it but also hold the whip that threatens them. I decide whether this case goes to the police or not... And I sometimes struggle with the law and it makes it difficult for me to talk to the family that needs time to contain the abuse... and it is stuck in your brain that the case can reach the police 
and prevents them (parents) from acting in favor of the victim, the perpetrator, the other siblings, the family... For me, the default in such cases must be an Exemption Committee' (JCAC, group no. 2).

However, this opinion was not accepted by all members of the JCAC, and some participants raised concerns about the unknown consequences for the victims when referring the family to therapy rather than to legal proceedings, perceiving it as possibly unfair towards the victims themselves, as illustrated in the following quote:

'No one has examined the consequences of long-term police reporting [in cases of SSA]. We see the whirlwind in the short term. In the long term, it is not certain that mandatory reporting is destructive. As a victim I might want the police process because the offender ruined my life... Where is our responsibility as to how she will feel for another 10 years? This abuse cannot be deleted. I do not see therapy as a cure for such wounds... Where are the eyes of the little girl who wants to punish or take revenge so that the person will pay the price?' (JCAC, group no.1)

In sum, SSA cases pose unique difficulties and challenges for the CAC professionals in both countries. Their perceptions of their roles, primarily protecting the victim and other community members, versus protecting both the victim and family as a whole, also shapes the intervention process itself. While the US CAC members are compelled by the duty to report to police, which dictates their legal intervention, the members of the Israeli CAC can use the mechanism of the Exemption Committee, in order to take a more therapeutic route. However, this also creates complex dilemmas. Some of the participants see the Exemption Committee as a necessary tool and prefer therapy over legal interventions, while other Israeli participants recoil from frequent use of these committees, doubting whether one Exemption Committee provides justice to the victims in the short and long term.

\section{Discussion}


In the last few decades there have been major developments in the empirical literature concerning sexual abuse, including the emergence of SSA literature. Yet our understanding of SSA is still in its infancy and many of its aspects have yet to be understood (Fontana, 2001; Lafleur, 2009). One of the main challenges we face is to further the understanding of SSA characteristics as well as available legal and therapeutic interventions (Ballantine, 2012). Accordingly, this study was designed to enrich our understanding regarding perceptions and interventions in SSA cases by qualitatively analyzing CACs’ professionals’ perceptions and by comparing two CACs, one located in Jerusalem, Israel and another in Montgomery County, Pennsylvania, USA.

Though located in two different countries, the two CACs share multiple similarities. Participants from both CACs perceived cases of SSA as the most difficult and complex cases they encounter during the course of their work. Indeed, these perceptions are consistent with empirical findings presenting SSA as a serious and complex problem (Ballantine, 2012) with long-term implications for all involved and one that presents a challenge and raises many dilemmas among professionals in the field (Tapara, 2012).

The empirical and clinical literature dealing with the phenomenon of SSA often focuses on the entire family as the focus for intervention, rather than focusing on the victim alone (Keane, Guest \& Padbury, 2013). Indeed, though created in order to protect victims of CSA, professionals in both CACs focused on the parental unit in cases of SSA, stressing the multiple negative feelings parents experienced after SSA disclosure and CAC intervention which may result in legal procedures. Indeed, the literature discusses the disclosure of SSA as placing families in a most difficult position (Tener \& Silverstein, submitted for publication), which often leads to a family crisis (Caffaro \& Conn-Caffaro, 2005). One tension that contributes to the creation of this crisis is that the parents remain responsible for all siblings, regardless of their “victim sibling” or "sibling with PSB” status (Bass et al., 2006; Lafleur, 2009), and find 
themselves struggling to act in their best interests (Daly \& Wade, 2014; Harper, 2012). Parents face intense emotional complexity when they are expected (by professionals) to adopt an unequivocal position in favor of the victim, when the sibling with PSB is also their child. Absolute support for the victim may also be perceived as coming at the expense of supporting the child with PSB as well (Caffaro, 2014; Welfare, 2010).

In this study, participants from both CACs emphasized the great difficulty for the parents to provide for the needs of both of their children. Both CACs' participants described how, in many of the cases, parents tended to support the sibling with PSB rather than the victim and, at times, were very uncooperative with the CAC legal interventions against the sibling with PSB. This finding is consistent with other findings in the research literature describing that families may choose to support the sibling with PSB (Tener, Luski, Tarshish \& Turjeman, 2018), and as a result, the survivor may paradoxically become the object of blame, disbelief or minimization of abuse (Rowntree, 2007; Tener, Luski, Tarshish \& Turgeman, 2018). Participants in this study offer an interesting explanation for what may appear to be a puzzling and perhaps worrying tendency for parents to be sympathetic to the sibling with PSB at the expense of the victim sibling. Parents may perceive the victim sibling already to be in receipt of considerable agency support and to be in a relatively safe and stable situation at home. Siblings with PSB, by contrast, may not be in receipt of any therapeutic interventions, may face frightening legal processes, and may be removed from the family home, school, and other sources of familial support. Moreover, at the MKCAC most therapeutic interventions are not available for the child with PSB until after the legal interventions are concluded. It may be understandable, then, that the focus of parental conversations with professionals concerns the uncertain circumstances of the siblings with PSB.

What seemed to differentiate the MKCAC from the JCAC teams are their perceptions of the motivations of parents' responses during the intervention: In the MKCAC, the team 
primarily concentrated on the parents' level of cooperation during intervention, and on their ability to support the victims. By contrast, in most cases the JCAC team seemed more focused on the parental circumstances which led to the negative responses. Though some of them were frustrated by the parents' responses, most focused on the SSA being a family crisis and on the parents' situation as unbearable. Such differences may be explained by the differences in the structure of the interventions in the two CACs, which can explain the findings of the current study concerning the focus of intervention in cases of SSA. In the MKCAC, the focus of the legal intervention begins with forensic interviews for the victims, which can only be performed when legal investigation of the case has begun. The JCAC, on the other hand, though obligated by mandatory reporting, has more opportunities to balance therapeutic and legal procedures.

Mandatory reporting laws are described in the literature as shifting the focus of child protection systems to reporting and investigating, which highlights legal aspects such as gathering evidence and preparing for legal procedures over therapeutic roles (Melton, 2005). Yet, mandatory reporting in cases of SSA may contradict the empirical and clinical literature emphasizing the need to view SSA cases in the context of the family system as a whole, and to address all family members' needs throughout the intervention, as well as devoting attention to the special needs of the sibling subsystem (Bass et al., 2006; Caffaro \& Conn-Caffaro, 2005; Tapara, 2012; Keane, Guest \& Padbury, 2013).

The tendency of the MKCAC towards legal interventions as opposed to therapeutic interventions, as well as the clear dichotomy between victim and siblings with PSB, does not necessarily reflect the personal views of all US participants, but rather the legal mandate under which they operate. As opposed to the MKCAC, which is required to report cases of SSA to the police and cannot start therapeutic interventions unless legal interventions are being held, the JCAC is able to use the Exemption Committee (see introduction), a mechanism which enables more flexibility in immediate responses and the opportunity for a therapeutic role in 
the professionals' relationships with the families from the beginning of the report of SSA. The findings of the present study raise serious questions about how to best respond to SSA, and whether, and under what circumstances, it is best regarded as a family issue requiring a therapeutic intervention or an issue of criminality requiring a legal intervention. This will clearly be influenced by prevailing cultural perspectives and moral judgments regarding the priorities given to meeting the needs of victims and children with PSB.

\section{Limitations}

One limitation of this study is the type of sample used. We cannot generalize our qualitative results to other CACs around the world, as it was composed of only two single CACs, one located in Montgomery County, Pennsylvania, USA, and the other in Jerusalem, Israel. Furthermore, each one of these centers carries unique cultural and societal characteristics, which were not discussed in the current study. For example, the population which is served in the JCAC contains larger and more religious families then the MKCAC, while the MKCAC treats more cases of SSA involving non-biological siblings or SSA cases of single-parent families. These and other possible cultural differences were not discussed in the current study, and should be referred to in future studies. Another limitation may be that due to geographical challenges the primary researcher was able to speak with the JCAC team in person, whereas all MKCAC interviews, except for one, needed to be done via Skype. Further, due to the CAC construct the JCAC participants were interviewed as a team, but MKCAC participants were at times interviewed according to specialty, e.g., law enforcement and prosecution only, social work only, etc., as well as team interviews.

Moreover, the current study does not specifically address significant SSA characteristics described in the literature, which may affect professionals' perceptions and interventions, including the ages of all the siblings involved or the severity of the abuse. (Johnson, 2002; 2003). The present study has not specifically addressed the fundamental issue 
of the living arrangements after SSA is discovered i.e., in which cases do the professionals choose to remove the sibling with the PSB from the home versus leaving the siblings both under the same roof, and might these decisions involve cultural differences? One of the findings of this study was that members of the MKCAC team would not initiate therapeutic intervention if the sibling with the PSB did not leave the home. By contrast, in Yates' study (2015), which addressed social workers' decision-making in cases of SSA in Scotland, the social workers tended to try to keep the siblings together. Of note, the CAC model has not been adopted in Scotland, and therefore another study would be to compare the responses of interventions based on the CAC model in use in different cultures and include cultures which have not adopted the CAC model in response to SSA and other CSA cases. Other significant factors in interventions in SSA cases were also not discussed during the current study, including the criteria for deeming sibling sexual behavior as abusive, and the meaning of the ages of all the siblings involved, the age gaps between them, the duration of the abuse, and siblings' birth relations (biological or other types of sibling ties). All of these issues should be addressed in future, cross-cultural comparison studies.

In addition, as discussed, professionals from both CACs in the present study focused on parents' lack of cooperation and defensiveness during intervention. We question whether or to what extent parents may be defensive as they are feeling accused. If a parent abuses a child, in general we think about an offending and a non-offending parent - one of the parents is "innocent." However, in situations where a child in the family has abused another child, do both non-offending parents feel that they did something wrong and therefore the whole family structure is questioned because of the abuse taking place in the very heart of the family? This can be significant, since studies indeed reveal that familial factors such as siblings sharing a bed; parent-child incest; witnessing parental physical fighting; and family nudity can be associated with SSA (Griffee et al., 2016). In addition, the professionals at the two CACs 
described how parents sometimes choose to support the sibling with the PSB. However, we had no information on the circumstances in which parents may support the sibling with PSB, the victim sibling, or both, and how staff responded to parents in these different circumstances. These issues concerning the parental unit in cases of SSA did not emerge during the discussions with professionals in the focus groups, but should be explored in future studies with professionals and families.

Furthermore, this study did not address deeper issues in relation to the sibling with the PSB themselves. The literature talks about how siblings with PSB may also have a history of sexual abuse themselves, within or outside the family (Latzman, Viljoen, Scalora \& Ullman, 2011; Tidefors, Arvidsson, Ingevaldson \& Larsson, 2010), and that this may affect the intervention. Further studies should focus on interventions in cases of sexually abusive siblings and how interventions are affected by the abuse history of the sibling with PSB. Moreover, the JCAC provides initial crisis interventions to the child with PSB under the age of 12, however, it is not known to what the degree the initial intervention is beneficial, or not.

\section{Implications for Theory, Field Practice and Future Research}

The present study, although small and exploratory, has profound implications for policy and interventions in cases of SSA. The findings of the study show that despite the cultural differences, CAC professionals see SSA as a unique and complex phenomenon that differs from other cases of abuse. CACs act under mandatory reporting laws, which require them to deal with SSA in a similar way to other cases of CSA, although SSA cases may require a different intervention to suit their special character. The present study found that while professionals in MKCAC focus on the legal point of view, professionals in JCAC frequently debate between legal and therapeutic interventions. This is made possible by the framework in Israel that allows them to apply to the Exemption Committee and to receive exemption from the obligation to report. 
Cases of sibling sexual abuse require a renewed look at policies of interventions. SSA constitutes a profound family crisis stretching far beyond the abuse itself, and requires policies that will enable the entire family to receive interventions that will promote healing and not additional harm. The advantage of the Exemption Committee model is that it enables the CAC group members to examine each case in a complex and nuanced way, with reference to a range of factors simultaneously, including: (1) possible consequences for the victim and his/her wishes; (2) the ability of the sibling with PSB to take responsibility for his/her actions and to be obligated to receive treatment and rehabilitation; (3) the extent of the parents' cooperation in therapy and their ability to prevent further harm; and (4) abuse characteristics including severity, duration, and age gaps between siblings. The model of the Exemption Committee that exists in Israel can be a good alternative to cases of SSA, and can be applied in other countries as well.

However, the Exemption Committee model has not been sufficiently studied and future research should focus on the Exemption Committee in an attempt to understand how it operates, the considerations of social workers when choosing to apply for an exemption, and the considerations taken into account by the committee in making decisions to grant the exemption. It is important to further examine whether a path for some families involving both legal and therapeutic intervention concurrently may be appropriate and under what contexts and conditions. It is also necessary to examine the extent to which the model fits into other cultural contexts outside of Israel. Additionally, future research should study the long-term implications of each of both legal and therapeutic interventions on the lives and well-being of SSA families, in order to better understand the impact of these intervention on their lives. The professionals working with these families in the communities should also be a focus of further research. 
Future studies may benefit from an applied mixed-methods design to broaden our knowledge of the epidemiology as well as of the characteristics of SSA in CACs in different locations, settings and cultures. Such studies should consider all siblings involved, their caregivers, professionals as well as communities' and their protective capacity. These studies can influence both the policy of reporting cases of sibling sexual abuse and intervention in these complex, challenging and difficult cases.

\section{References}

Allardyce, S., \& Yates, P. (2013). Assessing risk of victim crossover in children and young people who display harmful sexual behaviors. Child Abuse Review, 22(4), 255-267.

Allen, B. (2017). Children with sexual behavior problems: Clinical characteristics and relationship to child maltreatment. Child Psychiatry \& Human Development, 48(2), 189199.

Atwood, J. D. (2007). When love hurts: Preadolescent girls' reports of incest. The American Journal of Family Therapy, 35(4), 287-313.

Ballantine, M. W. (2012). Sibling incest dynamics: Therapeutic themes and clinical challenges. Clinical Social Work Journal, 40(1), 56-65.

Bank, S. P., \& Kahn, M. D. (1982). The sibling bond. New York, NY: Basic Books.

Bass, L. B., Taylor, B. A., Knudson-Martin, C., \& Huenergardt, D. (2006). Making sense of abuse: Case studies in sibling incest. Contemporary Family Therapy, 28(1), 87-109.

Beard, K. W., O’Keefe, S. L., Swindell, S., Stroebel, S. S., Griffee, K., Young, D. H., \& Linz, T. D. (2013). Brother-brother incest: Data from an anonymous computerized survey. Sexual Addiction \& Compulsivity, 20(3), 217-253.

Braun, V., \& Clarke, V. (2006). Using thematic analysis in psychology. Qualitative Research in Psychology, 3(2), 77-101.

Brennan, S. (2006). Sibling incest within violent families: Children under 12 seeking nurture. Health Sociology Review 15(3): 287-292.

Caffaro, J. V., \& Conn-Caffaro, A. (2005). Treating sibling abuse families. Aggression and Violent Behavior, 10(5), 604-623.

Caffaro, J. V. (2014). Sibling abuse trauma: Assessment and intervention strategies for children, families and adults. New York, NY: Routledge. 
Canavan, M. M., Meyer, W. J., \& Higgs, D. C. (1992). The female experience of sibling incest. Journal of Marital and Family Therapy, 18(2), 129-142.

Carlson, B. (2011). Sibling incest: Adjustment in adult women survivors. Families in Society: The Journal of Contemporary Social Services, 92(1), 77-83.

Carlson, B. E., Maciol, K., \& Schneider, J. (2006). Sibling incest: Reports from forty-one survivors. Journal of Child Sexual Abuse, 15(4), 19-34.

Cicirelli, V. G. (1995). Sibling relationships in cross-cultural perspective. In V. G. Cicirelli (Ed.). Sibling Relationships Across the Life Span (pp. 69-85). NY, Plenum Press.

Cope, D. G. (2014). Methods and meanings: Credibility and trustworthiness of qualitative research. Oncology Nursing Forum, 41(1), 89-91.

Corbin, J., \& Strauss, A. (2008). Basics of qualitative research: techniques and procedures for developing grounded theory. Los Angeles, CA: Sage Publications.

Creswell, J. W., \& Miller, D. L. (2000). Determining validity in qualitative inquiry. Theory into Practice, 39(3), 124-130.

Cyr, M., Wright, J., McDuff, P., \& Perron, A. (2002). Intrafamilial sexual abuse: Brother-sister incest does not differ from father-daughter and stepfather-stepdaughter incest. Child Abuse \& Neglect, 26(9), 957-973.

Daly, K. \& Wade, D. (2014). Sibling sexual abuse: Offending patterns and dynamics in Youth Justice Conferences. In A. Hayden, L. Gelsthorpe, V. Kingi \& A. Morris (Eds.). A restorative justice approach to family violence: Changing tack (pp. 185-195). Surrey: Ashgate Publishing.

Finkelhor, D. (1980). Sex among siblings: A survey on prevalence, variety, and effects. Archives of Sexual Behavior, 9(3), 171-194.

Fontana, L. A. (2001). The experience of sibling relationships in the voices of children: Systemic interviews of dyads following the trauma of sibling incest and its recovery (Doctoral dissertation). Oregon State University, Corvallis, Oregon. Retrieved from http://ir.library.oregonstate.edu/xmlui/bitstream/handle/1957/32875/FontanaLynnA2001. pdf?sequence $=1$.

Giarretto, H. (1978). Humanistic treatment of father-daughter incest. Journal of Humanistic Psychology, 18(4), 59-76.

Giarretto, H. (1982). A comprehensive child sexual abuse treatment program. Child Abuse \& Neglect, 6(3), 263-278.

Gomes-Schwartz, B., Horowitz, J. M., \& Cardarelli, A. P. (1990). Child sexual abuse: The initial effects. Newbury Park, CA: Sage Publications. 
Griffee, K., Swindell, S., O'Keefe, S. L., Stroebel, S. S., Beard, K. W., Kuo, S.-Y. \& Stroupe, W. (2016). Etiological risk factors for sibling incest: Data from an anonymous computer-assisted self-interview. Sexual Abuse, 28(7), 620-659.

Hardy, M. S. (2001). Physical aggression and sexual behavior among siblings: A retrospective study. Journal of Family Violence, 16(3), 255-268.

Harper, B. M. (2012). Moving families to future health: Reunification experiences after sibling incest (Doctoral dissertation). University of Pennsylvania, Philadelphia, Pennsylvania. Retrieved from: https://repository.upenn.edu/edissertations_sp2/26/.

Haskins, C. (2003). Treating sibling incest using a family systems approach. Journal of Mental Health Counseling, 25(4), 337.

Jackson, S. (2004). A USA survey of program services provided by child advocacy centers. Child Abuse \& Neglect, 28(4), 411-421.

Jones, L. M., Cross, T. P., Walsh, W. A., \& Simone, M. (2007). Do Children's Advocacy Centers improve families' experiences of child sexual abuse investigations? Child Abuse \& Neglect, 31(10), 1069-1085.

Keane, M., Guest, A., \& Padbury, J. (2013). A balancing act: A family perspective to sibling sexual abuse. Child Abuse Review, 22(4), 246-254.

Kiselica, M. S., \& Morrill-Richards, M. (2007). Sibling maltreatment: The forgotten abuse. Journal of Counseling and Development, 85(2), 148-160.

Krienert, J. L., \& Walsh, J. A. (2011). Sibling sexual abuse: An empirical analysis of offender, victim, and event characteristics in National Incident-Based Reporting System (NIBRS) Data, 2000-2007. Journal of Child Sexual Abuse, 20(4), 353-372.

Lafleur, C. T. (2009). Mothers' reactions to disclosures of sibling sexual abuse (Unpublished doctoral dissertation). Kansas State University, Manhattan, Kansas.

Lamb, S., \& Edgar-Smith, S. (1994). Aspects of disclosure mediators of outcome of childhood sexual abuse. Journal of Interpersonal Violence, 9(3), 307-326.

Latzman, N. E., Viljoen, J. L., Scalora, M. J., \& Ullman, D. (2011). Sexual offending in adolescence: A comparison of sibling offenders and nonsibling offenders across domains of risk and treatment need. Journal of Child Sexual Abuse, 20(3), 245-263.

Lincoln, Y. S., \& Guba, E. G. (1985). Naturalistic inquiry. Beverly Hills, CA: Sage Publications.

Lynch, D. L., Stern, A. E., Kim Oates, R., \& O'Toole, B. I. (1993). Who participates in child sexual abuse research? Journal of Child Psychology and Psychiatry, 34(6), 935-944. 
Maykut, P., \& Morehouse, R. (1994). Beginning qualitative research: a philosophic and practical approach. Washington, DC: Falmer.

McDonald, C., \& Martinez, K. (2017). Victims’ Retrospective Explanations of Sibling Sexual Violence. Journal of Child Sexual Abuse, 26(7), 874-888.

Melton, G. B. (2005). Mandated reporting: a policy without reason. Child Abuse \& Neglect, 29(1), 9-18.

Meyers, A. (2017). Lifting the veil: The lived experience of sibling abuse. Qualitative Social Work, 16(3), 333-350.

Miller, A., \& Rubin, D. (2009). The contribution of children's advocacy centers to felony prosecutions of child sexual abuse. Child Abuse \& Neglect, 33(1), 12-18.

Monahan, K. (2010). Themes of adult sibling sexual abuse survivors in later life: An initial exploration. Clinical Social Work Journal, 38(4), 361-369.

Morgan, D. L. (1998). The focus group guide book. London: Sage Publications.

Morrill, M. (2014). Sibling sexual abuse: an exploratory study of long-term consequences for self-esteem and counseling considerations. Journal of Family Violence, 29(2), 205-213.

Nahmani Roth, D. (2010). The conditions for exempting welfare officers from the obligation to report offences against children to the police. Mishpacha VeMishpat, C-D, 379-399 [In Hebrew].

Nowell, L. S., Norris, J. M., White, D. E., \& Moules, N. J. (2017). Thematic analysis: Striving to meet the trustworthiness criteria. International Journal of Qualitative Methods, 16, 113.

OECD. (n.d.). Israel Penal Law 5737-1977. Retrieved from: www.oecd.org/daf/antibribery/anti-briberyconvention/43289694.pdf

Onwuegbuzie, A. J., Dickinson, W. B., Leech, N. L., \& Zoran, A. G. (2009). A qualitative framework for collecting and analyzing data in focus group research. International Journal of Qualitative Methods, 8(3), 1-21.

Rasmusson, B. (2011). Children's advocacy centers (Barnahus) in Sweden. Child Indicators Research, 4(2), 301-321.

Rayment-McHugh, S., \& Nisbet, I. (2003, 1-2 May). Sibling incest offenders as a subset of adolescent sexual offenders. Paper presented at the Child Sexual Abuse: Justice Response or Alternative Resolution Conference, Adelaide.

Rowntree, M. (2007). Responses to sibling sexual abuse: Are they as harmful as the abuse? Australian Social Work, 60(3), 347-361. 
Rudd, J. M., \& Herzberger, S. D. (1999). Brother-sister incest-father-daughter incest: a comparison of characteristics and consequences. Child Abuse \& Neglect, 23(9), 915-928.

Russell, D. (1986). The secret trauma: Incest in the lives of girls and women. New York, NY: Basic Books.

Silovsky, J. F., \& Niec, L. (2002). Characteristics of young children with sexual behavior problems: A pilot study. Child Maltreatment, 7(3), 187-197.

Stroebel, S. S., O'Keefe, S. L., Beard, K. W., Kuo, S. Y., Swindell, S., \& Stroupe, W. (2013). Brother-sister incest: Data from anonymous computer-assisted self-interviews. Journal of Child Sexual Abuse, 22(3), 255-276.

Swisher, L. M., Silovsky, J. F., Stuart, J. R. H., \& Pierce, K. (2008). Children with sexual behavior problems. Juvenile and Family Court Journal, 59(4), 49-69.

Tapara, A. (2012). Best practice guidelines for health service professionals who receive initial disclosures of sibling sexual abuse. Kotuitui: New Zealand Journal of Social Sciences, 7(2), 83-97.

Tavkar, P., \& Hansen, D. J. (2011). Interventions for families victimized by child sexual abuse: Clinical issues and approaches for child advocacy center-based services. Aggression and Violent Behavior, 16(3), 188-199.

Tener, D., Tarshish, N., \& Turgeman, S. (2017). “Victim, perpetrator, or just my brother?” Sibling sexual abuse in large families: A child advocacy center study. Journal of Interpersonal Violence. Advance online publication. https://doi.org/10.1177/0886260517718831.

Tener, D., Luski, E., Tarshish, N. \& Turjeman, S. (2018). Parents therapeutic and legal experiences after the disclosure of sibling sexual abuse: results from analyzing cases of families in a child advocacy center. American Journal of Orthopsychiatry. Advance online publication. http://dx.doi.org/10.1037/ort0000311

Thomas, J. D., \& Viar, C. W. (2005). Family reunification in cases of sibling incest. In M. C. Calder (Ed.). Children and young people who sexually abuse: New theory, research and practice developments (pp. 354-371). Lyme Regis, UK: Russell House.

Thompson, K. M. (2009). Sibling incest: A model for group practice with adult female victims of brother-sister incest. Journal of Family Violence, 24(7), 531-537.

Tidefors, I., Arvidsson, H., Ingevaldson, S., \& Larsson, M. (2010). Sibling incest: A literature review and a clinical study. Journal of Sexual Aggression, 16(3), 347-360.

Veigh, M., \& Jo, M. (2003). 'But she didn’t say no': An exploration of sibling sexual abuse. Australian Social Work, 56(2), 116-126. 
Walsh, W., Cross, T. \& Jones, M. (2018). Do parents blame or doubt their child more when sexually abused by adolescents vs. adults? Journal of Interpersonal Violence, 27(3), 453470.

Welfare, A. (2010). Sibling sexual abuse: Understanding all family members' experiences in the aftermath of disclosure (Unpublished doctoral dissertation). La Trobe University, Melbourne.

Worling, J. R. (1995). Adolescent sibling-incest offenders: Differences in family and individual functioning when compared to adolescent nonsibling sex offenders. Child Abuse and Neglect 19(5): 633-643.

Yates, P. (2015). 'Better Together': a grounded theory study of social worker decision making in cases involving sexual behaviour between siblings (Doctoral dissertation). University of Edinburgh. Retrieved from:

https://www.era.lib.ed.ac.uk/bitstream/handle/1842/16446/Yates2015.pdf?sequence=1\&i sAllowed $=\mathrm{y}$.

Yates, P. (2017). Sibling sexual abuse: why don't we talk about it? Journal of Clinical Nursing, 26(15-16), 2482-2494. 